\title{
Associations between Croatian Adolescents' Use of Sexually Explicit Material and Risky Sexual Behavior: A Latent Growth Curve Modeling Approach
}

Koletić, Goran; Štulhofer, Aleksandar; Tomić, Ivan; Knežević Ćuća, Jadranka

Source / Izvornik: International Journal of Sexual Health, 2019, 31, 77 - 91

Journal article, Accepted version

Rad u časopisu, Završna verzija rukopisa prihvaćena za objavljivanje (postprint)

https://doi.org/10.1080/19317611.2019.1567640

Permanent link / Trajna poveznica: https://urn.nsk.hr/urn:nbn:hr:131:503465

Rights / Prava: Attribution-NonCommercial-NoDerivatives 4.0 International/ImenovanjeNekomercijalno-Bez prerada 4.0 međunarodna

Download date / Datum preuzimanja: 2023-04-26

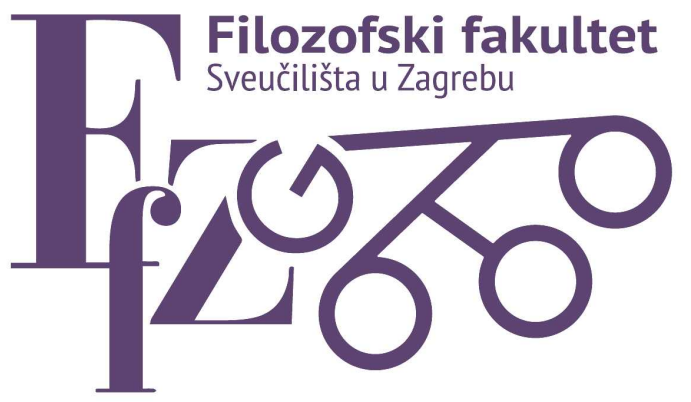

Repository / Repozitorij:

ODRAZ - open repository of the University of Zagreb Faculty of Humanities and Social Sciences
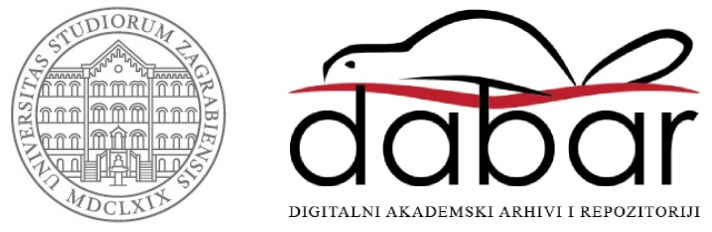


\title{
The Dynamics of Adolescents' Use of Sexually Explicit Material and Risky Sexual Behaviors: A Latent Growth Curve Modeling Approach *
}

\author{
Goran Koletić ${ }^{1}$ \\ Aleksandar Štulhofer ${ }^{1}$ \\ Ivan Tomić2 \\ Jadranka Knežević Ćuća ${ }^{3}$
}

${ }^{1}$ Department of Sociology, Faculty of Humanities and Social Sciences, University of Zagreb, Zagreb, Croatia

${ }^{2}$ Department of Psychology, Faculty of Humanities and Social Sciences, University of Zagreb, Zagreb, Croatia

${ }^{3}$ Department of Medical Biochemistry and Laboratory Medicine, Merkur University Hospital, Zagreb, Croatia

\section{Correspondence to:}

Goran Koletić,

Department of Sociology, Faculty of Humanities and Social Sciences University of Zagreb, Zagreb, Croatia

Ivana Lučića 3, 10000 Zagreb, Croatia

\footnotetext{
* Please cite this article as: Koletić, G., Štulhofer, A., Tomić, I., \& Knežević Ćuća, J. (2019). Associations between Croatian Adolescents' Use of Sexually Explicit Material and Risky Sexual Behavior: A Latent Growth Curve Modeling Approach. International Journal of Sexual Health, 31(1), 77-91. https://doi.org/10.1080/19317611.2019.1567640

This manuscript version is made available under the CC-BY-NC-ND 4.0 license http://creativecommons.org/licenses/by-nc-nd/4.0/.
} 
Phone/fax: +38514092042

E-mail: gkoletic@ @ffzg.hr

\section{Acknowledgement:}

This work has been supported by Croatian Science Foundation (project number 9221). Additional funding was provided by the University of Zagreb and the Atlantic Grupa d.d. 


\begin{abstract}
Objectives. The aim of this bio-behavioral longitudinal study was to assess the association between dynamics of SEM use and risky sexual behavior among Croatian adolescents.

Methods. The data were collected during 2015-2018 period $(n=577)$. Controlling for sensation seeking, socioeconomic status and pubertal timing, latent growth curve modeling with three observation points was used.

Results. Male adolescents' initial SEM use was related to sexual risk taking growth in the following months. Among female adolescents, SEM use and sexual risk taking were related only at the initial point.
\end{abstract}

Conclusions. Our findings suggest different developmental phases when addressing the target relationship.

Key Words: Adolescents, Adolescent Sexuality, Pornography, Risky Sexual Behavior, Longitudinal Assessment, Testosterone 
The Dynamics of Adolescents' Use of Sexually Explicit Material and Risky Sexual Behaviors: A Latent Growth Curve Modeling Approach

During their transition to adulthood, adolescents' health and wellbeing are often intertwined with various risk-taking behaviors. Sexual risk taking is among the main concerns primarily, but not solely, because of adolescents' vulnerability to sexually transmitted infections (STI) and unwanted pregnancy. Unprotected sexual intercourse at the age of 15-19 years was ranked second among global health-related mortality risk factors (Mokdad et al., 2016). In addition, World Health Organization (2011), Centers for Disease Control and Prevention (2017) and the European Centre for Disease Prevention and Control (2010) have warned about the high, and continuously increasing, prevalence rates of STIs among adolescents.

Increasing concerns among health experts, educators and general public have prompted studies focused on psychosocial and sociocultural influences on adolescent sexual risk taking (Dir, Coskunpinar, \& Cyders, 2014; Kotchick, Shaffer, Forehand, \& Miller, 2001; ZimmerGembeck \& Helfand, 2008). Pointing to links between the use of sexually explicit material (SEM) and adolescents' sexual behavior, a number of researchers have suggested the need to explore the role of SEM in young people's sexual risk taking (Harkness, Mullan, \& Blaszczynski, 2015; Koletić, 2017; Owens, Behun, Manning, \& Reid, 2012; Peter \& Valkenburg, 2016).

Recent technological advancements and affordability of mobile internet platforms have greatly facilitated access to SEM, making it also more accessible for adolescents. The increased use of SEM among adolescents has been repeatedly observed, provoking health-related concerns (Horvath et al., 2013; Martellozzo et al., 2016; Quadara, El-Murr, \& Latham, 2017). Although 
there is some evidence that SEM use and risky sexual behavior may be related in adolescence, but due to paucity of prospective (or retrospective) studies, little is known about the association between the dynamics of these constructs during the period from middle to late adolescence. This developmental period may be particularly important for at least two reasons. First, this is the time when most young people start to experiment with sexual behavior. Secondly, SEM use during this period may affect subsequent use by forming a long-lasting pattern (Willoughby, Young-Petersen, \& Leonhardt, 2018)—which can lead to increased sexual risk taking in emerging adulthood (Braithwaite, Coulson, Keddington, \& Fincham, 2015; Willoughby, Carroll, Nelson, \& Padilla-Walker, 2014).

\section{SEM Use and Sexual Risk Taking}

The existing evidence for the association between SEM use and risky sexual behavior in adolescence is mixed. In addition, the majority of the studies were cross-sectional, which precluded a dynamic (longitudinal) and more robust assessment of the association between SEM use and risky sexual behavior. An older cross-sectional study conducted only among female adolescents (Wingood et al., 2001) and another study with a predominantly female sample (Braun-Courville \& Rojas, 2009) found a positive relationship between SEM use and reporting multiple sexual partners. In contrast, a national probability-based study of Swiss adolescents (Luder et al., 2011) and a more recent convenience-based cross-sectional Australian study (Lim, Agius, Carrotte, Vella, \& Hellard, 2017) study reported nonsignificant associations between SEM use and multiple sexual partners. A significant association between SEM use and not using a condom at most recent sexual intercourse was found among female adolescents (Wingood et al., 2001), as well as male adolescents (Luder et al., 2011), but was not corroborated in the Australian study (Lim et al., 2017). Two longitudinal studies assessed the association between 
adolescents' SEM use and sexual risk taking. A two-wave study among a nationally representative sample of Dutch adolescents found no association between SEM use and casual sexual intercourse without using a condom (Peter \& Valkenburg, 2011). A recent nationally representative three-wave longitudinal study found that adolescents who started using SEM early and regularly were more likely to report multiple sexual partners, compared to low frequency SEM users (Rasmussen \& Bierman, 2018).

There are several possible explanations for the inconsistent and conflicting findings regarding SEM and adolescent sexual risk taking. First, there were notable differences in study samples in regard to age and gender. For example, a study by Lim at al. (2017) included $40 \%$ of adolescents, while other were young adults. The same study had less than $30 \%$ of male participants. Similar disproportion in gender was reported in Braun-Courville \& Rojas's study (2009). Secondly, mixed findings may reflect different measurement approaches to risky sexual behavior ranging from one-item measures (Peter \& Valkenburg, 2011) to nine-item composite risk index scores (Braun-Courville \& Rojas, 2009). The timeframe used also differed, as some studies included measures of sexual risk taking in the past 6 months, others in the past 12 months. Third, only one study included an objective indicator of risky sexual behavior by collecting vaginal specimens and testing for STI (Wingood et al., 2001). Finally, the studies were conducted in liberally legislated and sexually permissive countries of the developed West. More empirical insight from diverse cultural settings would enable a more systematic assessment of the link between adolescents' SEM use and risk-taking behaviors and, potentially, a better understanding of culture-specific aspects of the target relationship.

\section{Theoretical Framework}


Acquisition, Activation, and Application Model (3AM) of sexual media socialization (Wright, 2011) provides a conceptual framework for understanding possible socio-psychological mechanisms that underlie the association between adolescents' SEM use and risky sexual behavior. Based on the sexual scripting theory (Gagnon \& Simon, 2005) and, more generally, the cultivation model (Grebner, Gross, Morgan, Signorielli, \& Shanahan, 2002), the 3AM model posits that young people's sexual behavior is scripted (informed and oriented) and enacteddirectly or indirectly — by SEM use. According to this model, SEM provides specific sexual scripts (i.e., symbolic guidelines), which can influence adolescents' sexuality and actual sexual behaviors. By being exposed to the specific portrayal of sex in contemporary SEM-focused on casual sex or recreational pairing, rigidly defined gender roles, pleasure-oriented, and mostly condomless sexual encounters (Brosius, Weaver, \& Staab, 1993; Grudzen et al., 2009)— adolescents might perceive such practices as common and normative. In addition, SEM may encourage young people to experiment with multiple sexual partners (Braithwaite et al., 2015).

\section{The Current Study}

Given the need for a better understanding of the relationship between the dynamics of SEM use and adolescents' risky sexual behavior, the current study aimed to provide a robust longitudinal exploration of the target association. In addition, it included a biological component (assessment of testosterone levels) to contribute to a more comprehensive assessment by enabling insights into the role of maturation.

Informed by the existing research, we hypothesized that SEM use would be positively associated with risky sexual behavior among both male (Hypothesis 1) and female adolescents (Hypothesis 2). All analyses were carried out by gender due to different frequency of SEM use, different timing of first exposure to SEM and gender-specific sexual socialization (Doornwaard, 
van den Eijnden, Overbeek, \& Ter Bogt, 2015; Matković, Cohen, \& Štulhofer, 2018). Taking into account that biological factors have been found to predict adolescent sexual activity and sexual risk taking (Baams, Dubas, Overbeek, \& Van Aken, 2015; Halpern, Udry, \& Suchindran, 1998), we controlled for both subjective and objective indicators of pubertal timing and maturation when examining the target association. Sensation seeking and socioeconomic status were also controlled for due to potential links with risky sexual behavior in adolescence (Langille, Hughes, Murphy, \& Rigby, 2005; Luder et al., 2011; Peter \& Valkenburg, 2011; Santelli, Lowry, Brener, \& Robin, 2000).

Following recent recommendations (see Harkness et al., 2015; Koletić, 2017; Owens et al., 2012; Peter \& Valkenburg, 2016), this study contributes to the body of literature on the association between adolescent's SEM use and risky sexual behavior in several important aspects. First, by using three-wave panel data and a within-individual trajectory of change approach (i.e., latent growth curve modeling (LGCM; Curran, Obeidat, \& Losardo, 2010), we enabled insights into the associations between the dynamics of SEM use and risky sexual behavior. Second, in contrast to single-item measures of risky sexual behavior and informed by the trajectory-based research on adolescents' risky sexual behavior (Huang, Murphy, \& Hser, 2012; Moilanen, Crockett, Raffaelli, \& Jones, 2010), this study used a composite indicator of sexual risks, which provided a better assessment of measurement error. Third, this is the first longitudinal study of the link between adolescents' SEM use and risky sexual behavior to use both subjective and objective measures of biological maturation. Although biological measures are becoming more popular in adolescent health and sexuality research (Owens et al., 2012; Sales \& Irwin, 2013; van Anders, Goldey, \& Bell, 2014), we are unaware of a study similar to ours. Finally, by exploring the target association in a moderately socioeconomically developed 
Southeastern European country characterized by a strong Roman Catholic tradition and relatively restricted norms about sexuality (Luijkx, Halman, Sieben, Brislinger, \& Quandt, 2016; Štulhofer \& Rimac, 2009), this study provides material for cross-cultural contextualization of the links between adolescents' use of SEM and risk-taking sexual behavior.

Considering its potential to inform targeted interventions, this study's findings are relevant for experts in adolescent reproductive and sexual health, media literacy specialists, as well as for educational policy makers. Taking into account recent increase in social concerns over SEM-related harms (Quadara et al., 2017), our findings may also be of relevance to the general public, parents in particular.

\section{Method}

\section{Participants}

Data for this study were collected as part of the PROBIOPS research project that focused on longitudinal assessment of sexualized media use among Croatian adolescents. Adolescents in their second year were recruited from 14 out of 22 secondary schools in Rijeka, the third largest city in Croatia. Seven schools with less than 50 students were omitted due to financial constraints related to field work and one larger school because of a recent arson and burglary. The initial survey took place in December 2015 and the following five waves were spaced approximately 6 months apart. At the baseline (T0), 1,287 students correctly completed the questionnaire (63\% of the sophomore high-school student population; $\mathrm{M}_{\mathrm{age}}=15.8, \mathrm{SD}=0.51 ; 40.7 \%$ of male students). Analyses presented in this study were limited to the last three waves in which all indicators of risky sexual behavior were included. Number of participants in the last three waves were $n=$ 
1,176 (T3), $n=931$ (T4) and $n=892$ (T5), respectively. After the data cleaning ${ }^{\dagger}, 577$

participants completed a questionnaire at each wave and were eligible for the analyses.

Demographic information about the study participants are presented in Table 1.

School absenteeism and errors in filling out a unique 5-digit code used to link questionnaires across time were responsible for attrition. To address possible bias introduced by attrition, multivariate logistic regression analysis was carried out with the dependent variable representing those who participated in all three relevant data collection waves (participants included in this study were coded 0 ) and those who did not (coded 1). Indicators used in this study, measured at T3, served as independent variables. A single statistically significant difference between the two groups was observed: Participants who were excluded from this study were characterized by a less frequent SEM use at T3 SEM use compared to the participants included $(O R=.79, p=.039)$.

*** TABLE 1 ABOUT HERE ***

\section{Procedure}

Classroom-based self-administered paper and pencil surveying was used to collect data. To enhance confidentiality, portable screens were placed between participants and study coordinator remained in the classroom until the survey was completed. Informed consent material was presented by the study coordinator and printed at the first page of the questionnaire at each wave. A simple (unique) 5-letter identification code was used to link participants' questionnaires. No incentives were used in the Rijeka panel. Contact information for an online

\footnotetext{
${ }^{\dagger}$ For example, participants who reported decreasing or highly inconsistent numbers of lifetime sexual partners in the subsequent waves were excluded from the analyses $(n=23)$.
} 
youth help service was provided at the end of each questionnaire. All study procedures were approved by the Ethical Research Committee of the **** blinded for anonymity ****.

Procedures and equipment for biological testing of testosterone (T) were pre-tested in May 2017 in a group of 40 18-year-old high-school students from a small urban setting. Recruitment leaflets for the main study were distributed in schools during the final data collection wave at the beginning of March 2018. Biological data collection was organized in a local youth club, Monday to Friday from noon to 2 PM. After informed consent was obtained, participants were asked to fill out a brief questionnaire about their behaviors in the past 24 hours and chronic conditions that could influence T-levels (e.g., sexual activity, hours of sleep, bleeding gums, etc.). Only participants of legal age who participated in at least two study waves (of the total of six) were eligible for the biological component. Biological data was linked to survey data using the same 5-digit alphanumerical code which participants would generate at each study wave. Participation was awarded with a $6.5 €(\$ 7.5)$ shopping mall voucher.

In total, 252 saliva samples were collected-more than $80 \%$ of them between 1 and 3 PM — by passive drool using Salimetrics' Saliva Collection Aid and cryovials and stored at $70^{\circ} \mathrm{C}$ until required for analysis. After thawing, each sample was centrifuged for ten minutes at $2245 \mathrm{~g}$ at least once to separate the mucins. Clear colorless supernatants were then tested. Salivary $\mathrm{T}$ levels were measured in triplicate using a commercial enzyme-linked immunosorbent assay (Testosterone free in saliva ELISA test kit \#DES6622, Demeditec) according to manufacturer's instructions. The average intra-assay and inter-assay coefficients of variation for the $\mathrm{T}$ assay employed in the current study were $6,7 \%$ and 5,6\% respectively. The range of the assay, as determined by manufacturer, was $10-1000 \mathrm{pg} / \mathrm{ml}$. The lowest analytically detectable T 
level (i.e., distinguishable from the Zero Calibrator) was $2.2 \mathrm{pg} / \mathrm{ml}$ at $-/+2 S D$ limit. Certificates of quality control were provided for all ELISA kits.

\section{Measures}

Following the approach used in the 2005 population-based study of sexual risk taking among emerging Croatian adults (Štulhofer et al., 2009), we used a 6-item composite scale (the Index of Sexual Risk Taking; ISRT) to assess sexual risk taking. The scale included the following indicators: (1) condom use at most recent sexual intercourse (Have you and/or your partner used a condom at most recent sexual intercourse?), (2) one-night stand experience (Have you ever had sexual intercourse with a person whom you had just met and knew very little of nothing about?), (3) inconsistency of condom use (Have you and your partner used condom at each and every sexual intercourse during last six months?), (4 and 5) intoxication prior to sexual intercourse (How often did you drink alcohol just before sexual intercourse? and How often were you under the influence of drugs during sexual intercourse?)", and (6) the number of sexual partners (In total, with how many different people did you have a sexual intercourse?). Following the literature on adolescents' sexual risk taking (Santelli, Brener, Lowry, Bhatt, \& Zabin, 1998; Vasilenko \& Lanza, 2014), the number of sexual partners was dichotomized into $0=$ One sexual partner and $1=$ Two or more sexual partners. The ISRT was computed at each study wave.

Pornography use was measured at each time point and defined in the questionnaire as any material which openly (i.e., not censored) depicts sexual activity. Material which shows naked bodies but not sexual intercourse or other sexual activity does not belong to pornography as here defined. The item (How often have you used pornography during the last 6 months)

\footnotetext{
${ }^{*}$ Both questions had a 4-point scale $(1=$ Never to $4=$ Often $)$ to record answers. The indicators were dichotomized into $0=$ Never and $1=$ At least once) .
} 
included the following responses: $1=$ Never, $2=$ Several times, $3=$ Once $a$ month, $4=2-3$ times a month, $5=$ Once a week, $6=$ Several times $a$ week, $7=$ Every day or almost every day and $8=$ Several times a day.

Control variables. Male adolescents' maturation was assessed by measuring their Tlevels $(M=109,13 ; S D=54,36)$. Higher T-levels indicate more advanced developmental status (Shirtcliff, Dahl, \& Pollak, 2009). As biological testing was carried out only among male adolescents, retrospective self-assessment of relative pubertal timing at the final wave was used to estimate female participants' physical maturation (Compared to your peers, would you say that you have entered puberty...). The response scale ranged from $1=$ Much earlier than most of my peers to $5=$ Much later. The indicator, which has been shown to adequately measure relative onset of puberty (Michaud, Suris, \& Deppen, 2006; Wichstrom, 2011), was dichotomized into 1 $=$ early maturing adolescents (original categories 1 and 2; 21.6\%) and $0=$ others (categories 3-5). Family socioeconomic status was assessed at T3 by the Family Affluence Scale (FAS II), the recommended procedure for health-related research among adolescents (Boyce, Torsheim, Currie, \& Zambon, 2006). Sensation seeking was measured with The Brief Sensation Seeking Scale (Stephenson, Hoyle, Palmgreen, \& Slater, 2003). The 4-item measure was included in each study wave (Cronbach's $\alpha$ ranged from .80 to .83 and stability coefficients from .76 to .79).

\section{Analytical Strategy}

Confirmatory factor analysis of the ISRT was performed using a robust variant of diagonally weighted least squares estimator (WLSMV) separately for each time wave. This estimator was specifically chosen to account for dichotomous indicators in measurement models. Raw indicator values were weighted with corresponding factor loadings and averaged into wavespecific ISRT scores. Participants who did not report sexual intercourse in the past six months 
were assigned an ISRT score of 0. Guttman's lower bound ISRT reliability for waves T3-T5 were $\lambda_{T 3}=.53, \lambda_{T 4}=.68, \lambda_{T 5}=.73$.

The association between adolescents' SEM use and sexual risk score was analyzed using dual-domain (parallel) latent growth curve modeling (LGCM), an analytical method based on structural equation framework. It enables the assessment of between-person differences over time by estimating within-person latent trajectories of change (Curran et al., 2010; Duncan \& Duncan, 2009). Advantages of this method include unproblematic handling of unequal measurement occasions and missing information (LGCM uses full information maximum likelihood estimation; Enders \& Bandalos, 2001), as well as more robust treatment of nonnormally distributed measures and bias introduced by attrition rate (Curran et al., 2010; Little, 2013).

Analyses were carried out in three steps. First, linear and an unspecified (cumulative) growth curves were specified and compared using the standard chi-square difference test separately for the frequency of SEM use and the ISRT. Following recommendations (cf. Little, 2013), equality constraints were placed on indicators' error terms, separately by construct. Latent slope weights were set to reflect unequal periods between measurement points $(0,1,1.8)$. For both SEM use and ISRT, the more parsimonious (linear) curve was superior to the cumulative one.

Next, latent factors' means and variances were examined in an unconditional dualdomain model, separately by gender (see Table 2). With the exception of male participants' change in SEM use, all latent factor means and variances were significant, the latter pointing to substantial individual variation around group means. Due to the lack of significant growth in SEM use over time, the male model was reduced, following recommendations (Grimm, Ram, \& 
Estabrook, 2017), into an intercept-only model. ${ }^{\S}$ Compared to the full model, the intercept-only model had undistinguishable fit $\left(\Delta \chi^{2}(5)=4.46, p=.485\right)$.

In the final step we tested a conditional model by gender, in which pubertal timing and family socioeconomic status were included as time-invariant and sensation seeking as timevariant predictors of SEM and sexual risk taking.

\section{*** TABLE 2 ABOUT HERE ***}

To account for higher-level (classes) clustering effect, multilevel regression modeling with maximum likelihood estimation was conducted. ${ }^{* *}$ We calculated intraclass correlation (ICC) for SEM use and the ISRT separately by gender, using the intercept-only models. The classroom level accounted for 3.0\% of variance in male adolescents' SEM use and $7.1 \%$ of variance in the ISRT. Proportions for female adolescents were $2.9 \%$ and $7.6 \%$, respectively. Due to low ICC, data nestedness was ignored in LGCM. All analyses were carried out using IBM SPSS 25 and AMOS 23 statistical software packages.

\section{Results}

*** TABLE 3 ABOUT HERE ***

A small minority of male participants reported no use of SEM in the past six months (11.3\% at $\mathrm{T} 3$ and $7.1 \%$ at T5). Among their female peers, the respective proportions were 59.9\% and $57.5 \%$. During the observed period, an increase in the prevalence of risky behaviors was observed in both genders (see Table 2). Figure 1 presents the dynamics of average SEM use and the ISRT scores. Unlike with SEM use, there was a consistent increase in the scores over time in both genders. Some change in SEM use is observed between T3 and T4 in male adolescents and

\footnotetext{
$\S$ This transformation rendered direct comparisons across gender (using multi-group analysis) impossible.

** Because of the small number of schools $(n=14)$ in the sample, only nestedness in classes was examined.
} 
between T4 and T5 among their female peers. As presented in Table 4, significant positive associations between SEM use and the ISRT scores, mostly of small size, were observed consistently among female participants. In male participants, the associations were significant in five of nine instances.

\section{*** FIGURE 1 ABOUT HERE *** \\ *** TABLE 4 ABOUT HERE ***}

\section{Dynamics of SEM Use and Risky Sexual Behavior}

In the male sample, unconditional dual-domain model had excellent fit $\chi_{(16)}^{2}=11.41$, $\mathrm{CFI}=.99, \mathrm{RMSEA}=.016,90 \% \mathrm{CI}=.000-.043)$. We found a significant association between the baseline levels and subsequent growth in the ISRT scores $(r=.31, p=.029)$, pointing that individuals who reported higher sexual risk taking at T3 were characterized by a higher growth in risk taking over time (Figure 2). Importantly, initial frequency of SEM use was positively associated with change in sexual risk taking $(r=.26, p=.022)$. Male adolescents who used SEM more frequently at baseline reported steeper increase in the ISRT scores.

The conditional model was characterized by good fit $\left(\chi^{2}(34)=49.48, \mathrm{CFI}=.98, \mathrm{RMSEA}=\right.$ $.046,90 \% \mathrm{CI}=.009-.072)$. The addition of the three control variables resulted in no substantial change in either the association between sexual risk taking factors $(r=.34, p=.023)$ or the relationship between initial SEM use and growth in the ISRT scores $(r=.25, p=.027)$. Of the controls, only T-levels were significantly associated with baseline sexual risk taking $(\beta=.26, p=$ $.009)$.

\section{*** FIGURE 2 ABOUT HERE ***}

Unconditional model in the female sample had satisfactory fit $\chi_{(11)}^{2}=26.60, \mathrm{CFI}=.98$, RMSEA $=.058,90 \% \mathrm{CI}=.037-.088)$. Comparably to their male peers, initial levels and 
subsequent growth in female participants' sexual risk taking were positively associated $(r=.32$, $p<.001)$. We also observed a significant and positive relationship between baseline levels in the key constructs $(r=.37, \mathrm{p}=.002)$, pointing that female adolescents who initially reported higher SEM use also reported higher sexual risk taking (Figure 3).

The inclusion of the control variables improved the model fit $\left(\chi_{(27)}^{2}=45.42, \mathrm{CFI}=.99\right.$, RMSEA $=.043,90 \% \mathrm{CI}=.019-.065)$. The pattern of significant associations observed in the unconditional model remained unchanged, with the correlations attenuated by 1-3 percentage points. Pubertal timing was significantly related to baseline SEM use $(\beta=.23, p<.001)$, as well as to initial levels of sexual risk taking $(\beta=.20, p<.001)$. Compared to other female adolescents, early maturing adolescents used more SEM and reported higher levels of sexual risk taking at $\mathrm{T} 3$.

\section{*** FIGURE 3 ABOUT HERE ***}

\section{Discussion}

In the current morally-charged climate over young people's SEM use, the link between adolescents' risky sexual behavior and SEM use has received very limited attention in terms of methodologically robust longitudinal studies. To contribute to a better understanding of this association, we explored changes in the frequency of SEM use and risky sexual behavior over time. Using the three-wave panel data and the composite indicator of sexual risk taking, we applied dual-domain latent growth curve modeling to assess the target relationship.

According to Hypotheses 1 and 2, SEM use was expected to be positively related to the ISRT scores in both male and female adolescents. In the case of adolescent men, we found that more frequent SEM use at baseline significantly predicted subsequent growth in the composite sexual risk taking scores. Among female adolescents, the analysis revealed a positive 
relationship only between baseline SEM use and the ISRT scores. After controlling for T (in the male sample only), pubertal timing (in the female sample only), sensation seeking and socioeconomic status, we found no substantial change in the association between key constructs in either gender.

We found no growth in SEM use among male adolescents in the period under observation, which precluded any dynamic relationship with sexual risk taking. However, higher baseline frequency of SEM use predicted steeper increase in the ISRT scores in the subsequent 10 months. The finding might have been expected due to higher rates of SEM use (Doornwaard et al., 2015) and sexual risk taking among male adolescents (Kotchick et al., 2001; Štulhofer et al., 2009), compared to female adolescents. From the 3 AM perspective, SEM use in an earlier developmental period might have provided sexual scripts that portray sexual practices as riskfree, thus decreasing the likelihood of responsible intentions ("I will use a condom when having sex") and, ultimately, of safer sex. This is suggested by Rasmussen and Bierman (2018) who found that adolescents who reported an early initiation into SEM use and regular onward use were more likely to report multiple sexual partners. Similarly, a study of emerging Croatian adults found an association between the timing of first exposure to SEM and risky sexual behavior, with participants who were exposed to SEM at an earlier age reporting higher sexual risk taking score than their peers (Sinković, Štulhofer, \& Božić, 2013). Overall, it is plausible that SEM-related scripting process during the period of early to middle adolescence contributes to the development of a pattern of sexual risk taking in late adolescence.

We found no evidence for a dynamic relationship between SEM use and sexual risk taking in female adolescents. The observed growth in sexual risk taking in the observed period was unrelated to the growth in SEM use. However, the significant association at the initial 
measurement does not allow us to rule out their dynamic interplay in an earlier developmental period. If so, there appears to be a gender-specific difference in the process. While earlier scripting appears to have ramifications for male sexual risk taking in late adolescence, in adolescent women the (possible) effect does not seem to continue into late adolescence. Alternatively, the baseline association between SEM use and ISRT scores in adolescent women may be a spurious relationship caused by a variable not included in this study.

Furthermore, developmental influences, such as psychophysiological maturation, are evident in the finding that T-levels in male adolescents and timing of the onset of puberty in female adolescents were significantly related to the ISRT scores. This is expected, because adolescents in more advanced pubertal stages are generally more prone to sexual risk taking (Baams et al., 2015). Maturation process is associated with sexual risk taking both "endogenously" and "exogenously". In the former case, the process of endocrinological and psychosocial maturation increases curiosity about sexuality and sexual interest. In the latter case, bodily manifestations of the maturation process are signals of sexual maturity to potential partners. If they are older and more sexually experienced, they may have more power in sexual decision making (including the use of protection) and are also more likely to be infected with an STI. Although mostly indirectly, our findings underline the importance of including the indicators of adolescent maturing in research on adolescent sexual behavior.

The associations between adolescent SEM use and sexual risk taking observed in this longitudinal study speak in favor of specific educational interventions. Some school-based media literacy and comprehensive sexuality education programs have been found to reduce risks related to the use of sexualized media (Jones, 2018; Vandenbosch \& van Oosten, 2017). By assisting young people in making sense of overt and covert media messages and the implicit norms (and 
behavioral standards) that they often convey, such programs may reduce vulnerability to risk taking and other adverse outcomes.

\section{Limitations and Future Directions}

Several study limitations should be considered. Three available data collection waves spanning over a 10-month period rendered a more precise estimation of latent trajectories in the key constructs impossible. Consequently, our assessment may have missed some developmental nuances. Future research should include more measurement occasions over a longer period of time to allow for more comprehensive and (developmentally) precise modeling of latent trajectories. Another limitation is the attrition bias, which may have affected the strength of the associations. As previously noted, the participants excluded from our analyses reported a less frequent baseline use of SEM compared to their included peers. It should be noted, however, that if this selection bias affected our findings, it likely overestimated rather than underestimated the target association. Finally, culture-specific character of our findings cannot be ruled out.

Future researchers should consider other potential confounders of the target association, such as impulsivity and sociosexuality (Charnigo, Noar, Garnett, Crosby, \& Zimmerman, 2015; Dir et al., 2014). Taking into account that both SEM use and risky sexual practices may be relationship-specific, adolescents' involvement in and beliefs about romantic relationships should also be considered (Fortenberry, Tu, Harezlak, Katz, \& Orr, 2002). Whenever possible, researchers should employ non-invasive biological measures. For example, urine-based Chlamydia trachomatis testing may be used to provide an objective indicator of sexual risk taking (Božičević et al., 2011; Wingood et al., 2001). Finally, considering that links between adolescents' SEM use and sexual risk taking are no longer of concern only in developed Western 
countries (see Arulogun, Ogbu, \& Dipeolu, 2016), the field would greatly benefit from systematic cross-cultural comparisons.

\section{Conclusions}

There is a growing public and professional concern about the link between adolescents' SEM use and their health-related vulnerability (Martellozzo et al., 2016; Quadara et al., 2017). To contribute to a better understanding of the relationship between adolescent SEM use and sexual risk taking, which has been hampered by a paucity of prospective assessments, this study explored the target association using longitudinal bio-behavioral data and a latent growth modeling approach. Our findings, which suggested a developmentally-specific association between SEM use and sexual risk taking in both genders, point to the importance of interventions aiming at increasing young people's skills to discern between the reality and its sexualized media portrayals.

\section{References}

Arulogun, O. S., Ogbu, I. A., \& Dipeolu, I. O. (2016). Influence of internet exposure on sexual behaviour of young persons in an urban district of Southwest Nigeria. Pan African Medical Journal, 25, 261. https://doi.org/10.11604/pamj.2016.25.261.2630

Baams, L., Dubas, J. S., Overbeek, G., \& Van Aken, M. A. G. (2015). Transitions in body and behavior: A meta-analytic study on the relationship between pubertal development and adolescent sexual behavior. Journal of Adolescent Health, 56(6), 586-598. https://doi.org/10.1016/j.jadohealth.2014.11.019

Boyce, W., Torsheim, T., Currie, C., \& Zambon, A. (2006). The Family Affluence Scale as a Measure of National Wealth: Validation of an Adolescent Self-Report Measure. Social Indicators Research, 78, 473-487. https://doi.org/10.2307/27522619 
Božičević, I., Grgić, I., Židovec-Lepej, S., Čakalo, J.-I., Belak-Kovačević, S., Štulhofer, A., \& Begovac, J. (2011). Urine-based testing for Chlamydia trachomatis among young adults in a population-based survey in Croatia: feasibility and prevalence. BMC Public Health, 11(1), 230. https://doi.org/10.1186/1471-2458-11-230

Braithwaite, S. R., Coulson, G., Keddington, K., \& Fincham, F. D. (2015). The Influence of Pornography on Sexual Scripts and Hooking Up Among Emerging Adults in College. Archives of Sexual Behavior, 44, 111-123. https://doi.org/10.1007/s10508-014-0351-x

Braun-Courville, D. K., \& Rojas, M. (2009). Exposure to sexually explicit Web sites and adolescent sexual attitudes and behaviors. The Journal of Adolescent Health : Official Publication of the Society for Adolescent Medicine, 45(2), 156-62.

https://doi.org/10.1016/j.jadohealth.2008.12.004

Brosius, H., Weaver, J. B., \& Staab, J. F. (1993). Exploring the social and sexual "reality" of contemporary pornography. Journal of Sex Research, 30(2), 161-170. https://doi.org/10.1080/00224499309551697

Centers for Disease Control and Prevention. (2017). Sexually Transmitted Disease Surveillance 2016. Atlanta, US: Department of Health and Human Services.

Charnigo, R., Noar, S. M., Garnett, C., Crosby, R., \& Zimmerman, R. S. (2015). Sensation Seeking and Impulsivity: Combined Associations with Risky Sexual Behavior in a Large Sample of Young Adults. Journal of Sexual Research, 50(5), 480-488. https://doi.org/10.1080/00224499.2011.652264.Sensation

Curran, P. J., Obeidat, K., \& Losardo, D. (2010). Twelve frequently asked questions about growth curve modeling. Journal of Cognition and Development, 11(2), 121-136. https://doi.org/10.1080/15248371003699969 
Dir, A. L., Coskunpinar, A., \& Cyders, M. A. (2014). A meta-analytic review of the relationship between adolescent risky sexual behavior and impulsivity across gender, age, and race. Clinical Psychology Review, 34(7), 551-562. https://doi.org/10.1016/j.cpr.2014.08.004

Doornwaard, S. M., van den Eijnden, R. J. J. M., Overbeek, G., \& Ter Bogt, T. F. M. (2015). Differential developmental profiles of adolescents using sexually explicit internet material. Journal of Sex Research, 52(3), 269-81. https://doi.org/10.1080/00224499.2013.866195

Duncan, T. E., \& Duncan, S. C. (2009). The ABC's of LGM: An Introductory Guide to Latent Variable Growth Curve Modeling. Social and Personality Psychology Compass, 3(6), 979991. https://doi.org/10.1111/j.1751-9004.2009.00224.x

Enders, C. K., \& Bandalos, D. L. (2001). The Relative Performance of Full Information Maximum Likelihood Estimation for Missing Data in Structural Equation Models. Structural Equation Modeling: A Multidisciplinary Journal, 8(3), 430-457. https://doi.org/10.1207/S15328007SEM0803_5

European Centre for Disease Prevention and Control. (2010). Sexually Transmitted Infections in Europe 1990-2010. Stockholm. https://doi.org/10.2900/89440

Fortenberry, J. D., Tu, W., Harezlak, J., Katz, B. P., \& Orr, D. P. (2002). Condom Use as a Function of Time in New and Established Adolescent Sexual Relationships. American Journal of Public Health, 92(2), 211-213. Retrieved from http://www.ncbi.nlm.nih.gov/pmc/articles/PMC1447044/

Gagnon, J. H., \& Simon, W. (2005). Sexual conduct: The social sources of human sexuality. Piscataway, NJ: Transaction.

Grebner, G., Gross, L., Morgan, M., Signorielli, N., \& Shanahan, J. (2002). Growing up with television: Cultivation processes. In J. Bryant \& D. Zillmann (Eds.), LEA's communication 
series. Media effects: Advances in theory and research (pp. 43-67). Mahwah, NJ: Lawrence Erlbaum Associates Publishers.

Grimm, K. J., Ram, N., \& Estabrook, R. (2017). Growth Modeling: Structural Equation and Multilevel Modeling Approaches. New York, NY: The Guilford Press.

Grudzen, C. R., Elliott, M. N., Kerndt, P. R., Schuster, M. A., Brook, R. H., \& Gelberg, L. (2009). Condom use and high-risk sexual acts in adult films: a comparison of heterosexual and homosexual films. American Journal of Public Health, 99 Suppl 1, 152-156. https://doi.org/10.2105/AJPH.2007.127035

Halpern, C. T., Udry, J. R., \& Suchindran, C. (1998). Monthly measures of salivary testosterone predict sexual activity in adolescent males. Archives of Sexual Behavior, 27(5), 445-65. Retrieved from http://www.ncbi.nlm.nih.gov/pubmed/9795726

Harkness, E. L., Mullan, B. M., \& Blaszczynski, A. (2015). Association between pornography use and sexual risk behaviors in adult consumers: a systematic review. Cyberpsychology, Behavior and Social Networking, 18(2), 59-71. https://doi.org/10.1089/cyber.2014.0343

Horvath, M., Alys, L., Massey, K., Pina, A., Scally, M., \& Adler, J. R. (2013). “Basically...porn is everywhere". A Rapid Evidence Assessment on the Effects that Access and Exposure to Pornography has on Children and Young People. Office of the Children's Commissioner. Retrieved from http://kar.kent.ac.uk/44763/1/BasicallyporniseverywhereReport.pdf Huang, D. Y. C., Murphy, D. A., \& Hser, Y.-I. (2012). Developmental Trajectory of Sexual Risk Behaviors From Adolescence to Young Adulthood. Youth \& Society, 44(4), 479-499. https://doi.org/10.1177/0044118X11406747

Jones, M. (2018, February 7). What Teenagers Are Learning From Online Porn. Retrieved from https://www.nytimes.com/2018/02/07/magazine/teenagers-learning-online-porn-literacy- 
sex-education.html

Koletić, G. (2017). Longitudinal associations between the use of sexually explicit material and adolescents' attitudes and behaviors: A narrative review of studies. Journal of Adolescence, 57, 119-133. https://doi.org/10.1016/j.adolescence.2017.04.006

Kotchick, B., Shaffer, A., Forehand, R., \& Miller, K. (2001). Adolescent sexual risk behavior: a multi-system perspective. Clinical Psychology Review, 21(4), 493-519. https://doi.org/10.1016/S0272-7358(99)00070-7

Langille, D. B., Hughes, J., Murphy, G. T., \& Rigby, J. A. (2005). Socio-economic factors and adolescent sexual activity and behaviour in Nova Scotia. Canadian Journal of Public Health = Revue Canadienne de Sante Publique, 96(4), 313-8. Retrieved from http://www.ncbi.nlm.nih.gov/pubmed/16625805

Lim, M. S. C., Agius, P. A., Carrotte, E. R., Vella, A. M., \& Hellard, M. E. (2017). Young Australians' use of pornography and associations with sexual risk behaviours. Australian and New Zealand Journal of Public Health, 41(4), 438-443. https://doi.org/10.1111/17536405.12678

Little, T. D. (2013). Longitudinal Structural Equation Modeling. New York: Guilford Press.

Luder, M.-T., Pittet, I., Berchtold, A., Akré, C., Michaud, P.-A., \& Surís, J.-C. (2011). Associations between online pornography and sexual behavior among adolescents: myth or reality? Archives of Sexual Behavior, 40(5), 1027-35. https://doi.org/10.1007/s10508-0109714-0

Luijkx, R., Halman, L., Sieben, I., Brislinger, E., \& Quandt, M. (2016). European Values in Numbers. Leiden: Brill. https://doi.org/10.1163/9789004328525

Martellozzo, E., Monaghan, A., Adler, J., Davidson, J., Leyva, R., \& Horvath, M. (2016). “I 
wasn't sure it was normal to watch it..." A quantitative and qualitative examination of the impact of online pornography on the values, attitudes, beliefs and behaviours of children and young people. London, UK: NSPCC. https://doi.org/doi:10.6084/m9.figshare.3382393

Matković, T., Cohen, N., \& Stulhofer, A. (2018). The Use of Sexually Explicit Material and Its Relationship to Adolescent Sexual Activity. Journal of Adolescent Health, 62(5), 563-569. https://doi.org/10.1016/j.jadohealth.2017.11.305

Michaud, P. A., Suris, J. C., \& Deppen, A. (2006). Gender-related psychological and behavioural correlates of pubertal timing in a national sample of Swiss adolescents. Molecular and Cellular Endocrinology, 254-255, 172-178. https://doi.org/10.1016/j.mce.2006.04.037

Moilanen, K. L., Crockett, L. J., Raffaelli, M., \& Jones, B. L. (2010). Trajectories of sexual risk from middle adolescence to early adulthood. Journal of Research on Adolescence, 20(1), 114-139. https://doi.org/10.1111/j.1532-7795.2009.00628.x

Mokdad, A. H., Forouzanfar, M. H. ossei., Daoud, F., Mokdad, A. A., El Bcheraoui, C., MoradiLakeh, M., ... Murray, C. J. L. (2016). Global burden of diseases, injuries, and risk factors for young people's health during 1990-2013: a systematic analysis for the Global Burden of Disease Study 2013. Lancet (London, England), 387(10036), 2383-2401. https://doi.org/10.1016/S0140-6736(16)00648-6

Owens, E. W., Behun, R. J., Manning, J. C., \& Reid, R. C. (2012). The Impact of Internet Pornography on Adolescents: A Review of the Research. Sexual Addiction \& Compulsivity, 19, 99-122. https://doi.org/10.1080/10720162.2012.660431

Peter, J., \& Valkenburg, P. M. (2011). The influence of sexually explicit Internet material on sexual risk behavior: a comparison of adolescents and adults. Journal of Health Communication, 16, 750-765. https://doi.org/10.1080/10810730.2011.551996 
Peter, J., \& Valkenburg, P. M. (2016). Adolescents and Pornography: A Review of 20 Years of Research. The Journal of Sex Research, 53(4-5), 1-23. https://doi.org/10.1080/00224499.2016.1143441

Quadara, A., El-Murr, A., \& Latham, J. (2017). The effects of pornography on children and young people: An evidence scan. Melbourne: Australian Institute of Family Studies. https://doi.org/10.4172/ijscp.1000118

Rasmussen, K. R., \& Bierman, A. (2018). Risk or Release ?: Porn Use Trajectories and the Accumulation of Sexual Partners. Social Currents. https://doi.org/10.1177/2329496518780929

Sales, J. M., \& Irwin, C. E. (2013). A Biopsychosocial Perspective of Adolescent Health and Disease. In Handbook of Adolescent Health Psychology (pp. 13-29). New York, NY: Springer New York. https://doi.org/10.1007/978-1-4614-6633-8_2

Santelli, J., Brener, N. D., Lowry, R., Bhatt, A., \& Zabin, L. S. (1998). Multiple sexual partners among U.S. adolescents and young adults. Family Planning Perspectives, 30(6), 271-5. Retrieved from http://www.ncbi.nlm.nih.gov/pubmed/9859017

Santelli, J. S., Lowry, R., Brener, N. D., \& Robin, L. (2000). The association of sexual behaviours with socioeconomic status, family structure and race/ethnicity among US adolescents. American Journal of Public Health, 90(10), 1582-1588. https://doi.org/http://dx.doi.org/10.2105/AJPH.90.10.1582

Shirtcliff, E. A., Dahl, R. E., \& Pollak, S. D. (2009). Pubertal development: correspondence between hormonal and physical development. Child Development, 80(2), 327-37. https://doi.org/10.1111/j.1467-8624.2009.01263.x

Sinković, M., Štulhofer, A., \& Božić, J. (2013). Revisiting the Association between Pornography 
Use and Risky Sexual Behaviors: The Role of Early Exposure to Pornography and Sexual Sensation Seeking. Journal of Sex Research, 50(7), 633-641.

https://doi.org/10.1080/00224499.2012.681403

Stephenson, M. T., Hoyle, R. H., Palmgreen, P., \& Slater, M. D. (2003). Brief measures of sensation seeking for screening and large-scale surveys. Drug and Alcohol Dependence, 72(3), 279-86. Retrieved from http://www.ncbi.nlm.nih.gov/pubmed/14643945

Štulhofer, A., Graham, C., Božičević, I., Kufrin, K., \& Ajduković, D. (2009). An Assessment of HIV/STI Vulnerability and Related Sexual Risk-Taking in a Nationally Representative Sample of Young Croatian Adults. Archives of Sexual Behavior, 38(2), 209-225. https://doi.org/10.1007/s10508-007-9234-8

Štulhofer, A., \& Rimac, I. (2009). Determinants of Homonegativity in Europe. Journal of Sex Research, 46(1), 24-32. https://doi.org/10.1080/00224490802398373

van Anders, S. M., Goldey, K. L., \& Bell, S. N. (2014). Measurement of Testosterone in Human Sexuality Research: Methodological Considerations. Archives of Sexual Behavior, 43(2), 231-250. https://doi.org/10.1007/s10508-013-0123-z

Vandenbosch, L., \& van Oosten, J. M. F. (2017). The Relationship Between Online Pornography and the Sexual Objectification of Women: The Attenuating Role of Porn Literacy Education. Journal of Communication, 67(6), 1015-1036. https://doi.org/10.1111/jcom.12341

Vasilenko, S. A., \& Lanza, S. T. (2014). Predictors of multiple sexual partners from adolescence through young adulthood. Journal of Adolescent Health, 55(4), 491-497. https://doi.org/10.1016/j.jadohealth.2013.12.025

WHO. (2011). A snapshot of the health of young people in Europe. Copenhagen: WHO Regional 
Office for Europe.

Wichstrom, L. (2011). The Impact of Pubertal Timing on Adolescents' Alcohol Use. Journal of Research on Adolescence, 11(2), 131-150. https://doi.org/10.1111/1532-7795.00007

Willoughby, B. J., Carroll, J. S., Nelson, L. J., \& Padilla-Walker, L. M. (2014). Associations between relational sexual behaviour, pornography use, and pornography acceptance among US college students. Culture, Health \& Sexuality, 16(December), 1052-1069. https://doi.org/10.1080/13691058.2014.927075

Willoughby, B. J., Young-Petersen, B., \& Leonhardt, N. D. (2018). Exploring Trajectories of Pornography Use Through Adolescence and Emerging Adulthood. Journal of Sex Research, 55(3), 297-309. https://doi.org/10.1080/00224499.2017.1368977

Wingood, G. M., DiClemente, R. J., Harrington, K., Davies, S., Hook, E. W., \& Oh, M. K. (2001). Exposure to X-rated movies and adolescents' sexual and contraceptive-related attitudes and behaviors. Pediatrics, 107(5), 1116-9. Retrieved from http://www.ncbi.nlm.nih.gov/pubmed/11331695

Wright, P. J. (2011). Mass Media Effects on Youth Sexual Behavior Assessing the Claim for Causality. Annals of the International Communication Association, 35(1), 343-385. https://doi.org/10.1080/23808985.2011.11679121

Zimmer-Gembeck, M. J., \& Helfand, M. (2008). Ten years of longitudinal research on U.S. adolescent sexual behavior: Developmental correlates of sexual intercourse, and the importance of age, gender and ethnic background. Developmental Review, 28(2), 153-224. https://doi.org/10.1016/j.dr.2007.06.001 
Table 1

Demographic Information about the Study Participants at the Baseline $(n=1,287)$ and

Participants Included in the Analyses $(n=577)$

\begin{tabular}{|c|c|c|}
\hline & $\begin{array}{c}\text { Participants at } \\
\text { baseline }\end{array}$ & $\begin{array}{l}\text { Participants } \\
\text { included in } \\
\text { the analyses }\end{array}$ \\
\hline & $n(\%)$ & $n(\%)$ \\
\hline \multicolumn{3}{|l|}{ Gender } \\
\hline Male & $524(40.7)$ & $212(36.7)$ \\
\hline Female & $763(59.3)$ & $365(63.3)$ \\
\hline \multicolumn{3}{|l|}{ School type } \\
\hline Gymnasium & $379(29.4)$ & $214(37.1)$ \\
\hline Other & 908 (70.6) & $363(62.9)$ \\
\hline \multicolumn{3}{|l|}{ Family type } \\
\hline Intact & 987 (76.7) & $419(81.2)$ \\
\hline Other & $300(23.3)$ & $97(18.8)$ \\
\hline \multicolumn{3}{|l|}{ Mother's education } \\
\hline College & $480(37.5)$ & $212(41.3)$ \\
\hline High school or less & $799(62.1)$ & $301(58.7)$ \\
\hline \multicolumn{3}{|l|}{ Father's education } \\
\hline College & $441(35.1)$ & $190(37.4)$ \\
\hline \multirow[t]{2}{*}{ High school or less } & $816(64.9)$ & $318(62.6)$ \\
\hline & $M(S D)$ & $M(S D)$ \\
\hline Age & $15.8(0.51)$ & $17.3(0.47)$ \\
\hline First year average grade & $3.59(0.60)$ & $3.73(0.56)$ \\
\hline
\end{tabular}


Table 2

Baseline Levels and Latent Growth in Dual-domain Model of Adolescent SEM Use and the Index of Sexual Risk Taking

\begin{tabular}{|c|c|c|c|c|}
\hline & \multicolumn{2}{|c|}{$\begin{array}{l}\text { Male participants } \\
\quad(n=212)\end{array}$} & \multicolumn{2}{|c|}{$\begin{array}{l}\text { Female participants } \\
\qquad(n=365)\end{array}$} \\
\hline & $M(S E)$ & $\sigma^{2}(S E)$ & $M(S E)$ & $\sigma^{2}(S E)$ \\
\hline \multicolumn{5}{|l|}{ SEM use } \\
\hline Latent intercept & $4.90(.14)^{* * *}$ & $2.99(.41)^{* * *}$ & $1.93(.08)^{* * *}$ & $1.82(.17)^{* * *}$ \\
\hline Latent slope & $.11(.06)$ & $.03(.11)$ & $.04(.03)$ & $.10(.04)^{* *}$ \\
\hline \multicolumn{5}{|l|}{ ISRT } \\
\hline Latent intercept & $.04(.01)^{* * *}$ & $.01(.00)^{* * *}$ & $.05(.01)^{* * *}$ & $.02(.01)^{* * *}$ \\
\hline Latent slope & $.02(.01)^{* * *}$ & $.01(.00)^{* * *}$ & $.03(.01)^{* * *}$ & $.01(.00)^{* * *}$ \\
\hline
\end{tabular}

Notes. $* p<.05 . * * p<.01 . * * * p<.001$ 
Table 3

Reported Risky Sexual Behaviors in the Rijeka Panel by Gender and Wave

\begin{tabular}{|c|c|c|c|c|c|c|}
\hline & \multicolumn{2}{|c|}{$\mathrm{T} 3$} & \multicolumn{2}{|c|}{$\mathrm{T} 4$} & \multicolumn{2}{|c|}{ T5 } \\
\hline & $n$ & $\%$ & $n$ & $\%$ & $n$ & $\%$ \\
\hline \multicolumn{7}{|l|}{ Male participants $(n=212)$} \\
\hline Reported 2 or more sexual partners & 29 & 13.7 & 42 & 19.8 & 55 & 25.9 \\
\hline $\begin{array}{l}\text { Did not use a condom at most } \\
\text { recent sexual intercourse }\end{array}$ & 9 & 4.2 & 20 & 9.4 & 25 & 11.8 \\
\hline Experienced one-night stand & 15 & 7.1 & 32 & 15.1 & 28 & 13.2 \\
\hline Consumed alcohol prior to sexual intercourse & 18 & 8.5 & 37 & 17.5 & 51 & 24.1 \\
\hline Consumed drugs prior to sexual intercourse & 8 & 3.8 & 12 & 5.7 & 16 & 7.5 \\
\hline Did not use a condom consistently & 17 & 8.0 & 28 & 13.2 & 39 & 18.4 \\
\hline \multicolumn{7}{|l|}{ Female participants $(n=365)$} \\
\hline Reported 2 or more sexual partners & 47 & 12.9 & 65 & 17.8 & 92 & 25.2 \\
\hline $\begin{array}{l}\text { Did not use a condom at most } \\
\text { recent sexual intercourse }\end{array}$ & 36 & 9.9 & 56 & 15.3 & 74 & 20.3 \\
\hline Experienced one-night stand & 5 & 1.4 & 19 & 5.2 & 19 & 5.2 \\
\hline Consumed alcohol prior to sexual intercourse & 53 & 14.5 & 81 & 22.2 & 103 & 28.2 \\
\hline Consumed drugs prior to sexual intercourse & 8 & 2.2 & 11 & 3.0 & 11 & 3.0 \\
\hline Did not use a condom consistently & 61 & 16.7 & 83 & 22.7 & 106 & 29.0 \\
\hline
\end{tabular}


Table 4

Descriptive Information about and Cross-Correlations between the Key Indicators

\begin{tabular}{|c|c|c|c|c|c|c|c|c|}
\hline & \multicolumn{6}{|c|}{ Cross-Correlations } & \multicolumn{2}{|c|}{$M(S D)$} \\
\hline & 1 & 2 & 3 & 4 & 5 & 6 & Male & Female \\
\hline (1) SEM use T3 & & $.78^{* *}$ & $.74^{* *}$ & $.30^{* *}$ & $.24^{* *}$ & $.25^{* *}$ & $4.87(2.08)$ & $1.95(1.52)$ \\
\hline (2) SEM use T4 & $.70^{* * *}$ & & $.79^{* *}$ & $.27^{* *}$ & $.21^{* *}$ & $.23^{* *}$ & $5.06(2.04)$ & $1.93(1.52)$ \\
\hline (3) SEM use T5 & $.70^{* * *}$ & $.70^{* *}$ & & $.28^{* *}$ & $.22^{* *}$ & $.27^{* *}$ & $5.06(2.07)$ & $2.03(1.58)$ \\
\hline (4) ISRT T3 & .11 & .08 & .07 & & $.75^{* *}$ & $.66^{* *}$ & $0.04(0.09)$ & $0.05(0.09)$ \\
\hline (5) ISRT T4 & $.15^{*}$ & $.17^{*}$ & .10 & $.63^{* *}$ & & $.79^{* *}$ & $0.06(0.11)$ & $0.08(0.12)$ \\
\hline (6) ISRT T5 & $.18^{* *}$ & $.19^{* *}$ & $.18^{* *}$ & $.56^{* *}$ & $.74^{* *}$ & & $0.08(0.13)$ & $0.09(0.13)$ \\
\hline
\end{tabular}

Notes. Zero-order correlation coefficients in the male sample are shown below the main

diagonal, while coefficients in the female sample are presented above it; weighted ISRT scores are presented; $* p<.05 . * * p<.01$. 

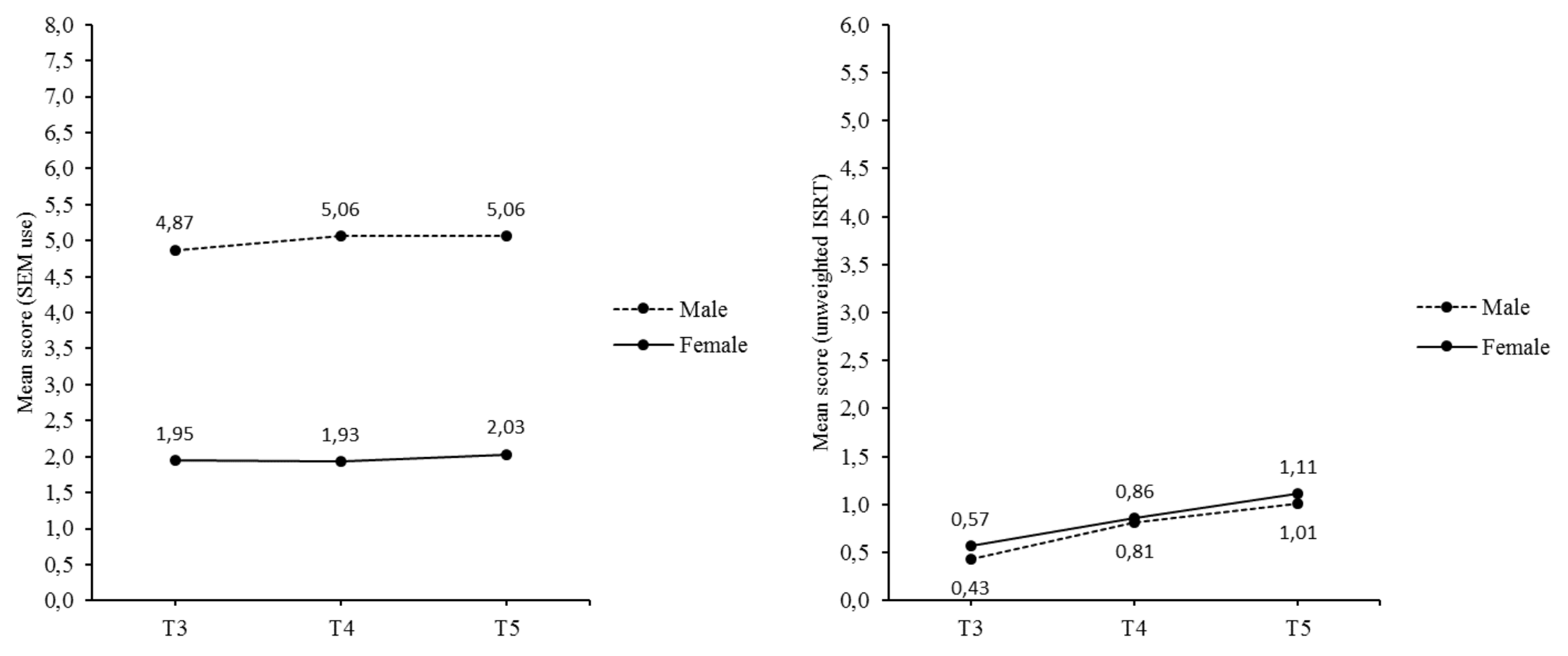

Figure 1. Dynamics of SEM Use and the Index of Sexual Risk Taking among Adolescents 


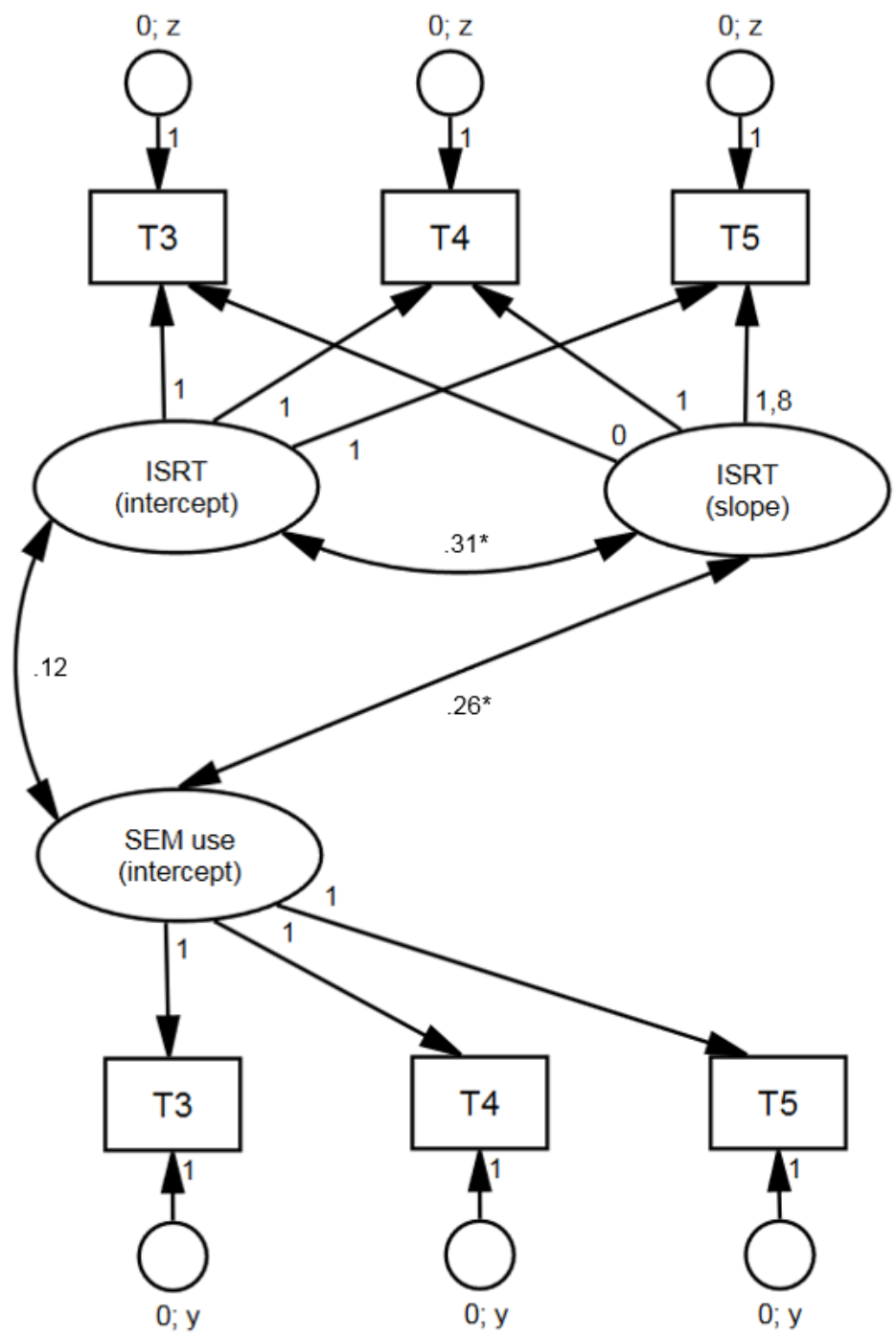

Figure 2. Latent Growth in Male Adolescents' SEM use and the Index of Sexual Risk Taking ( $n$ $=212$ ).

Note. $* p<.05 . * * p<.01$. 


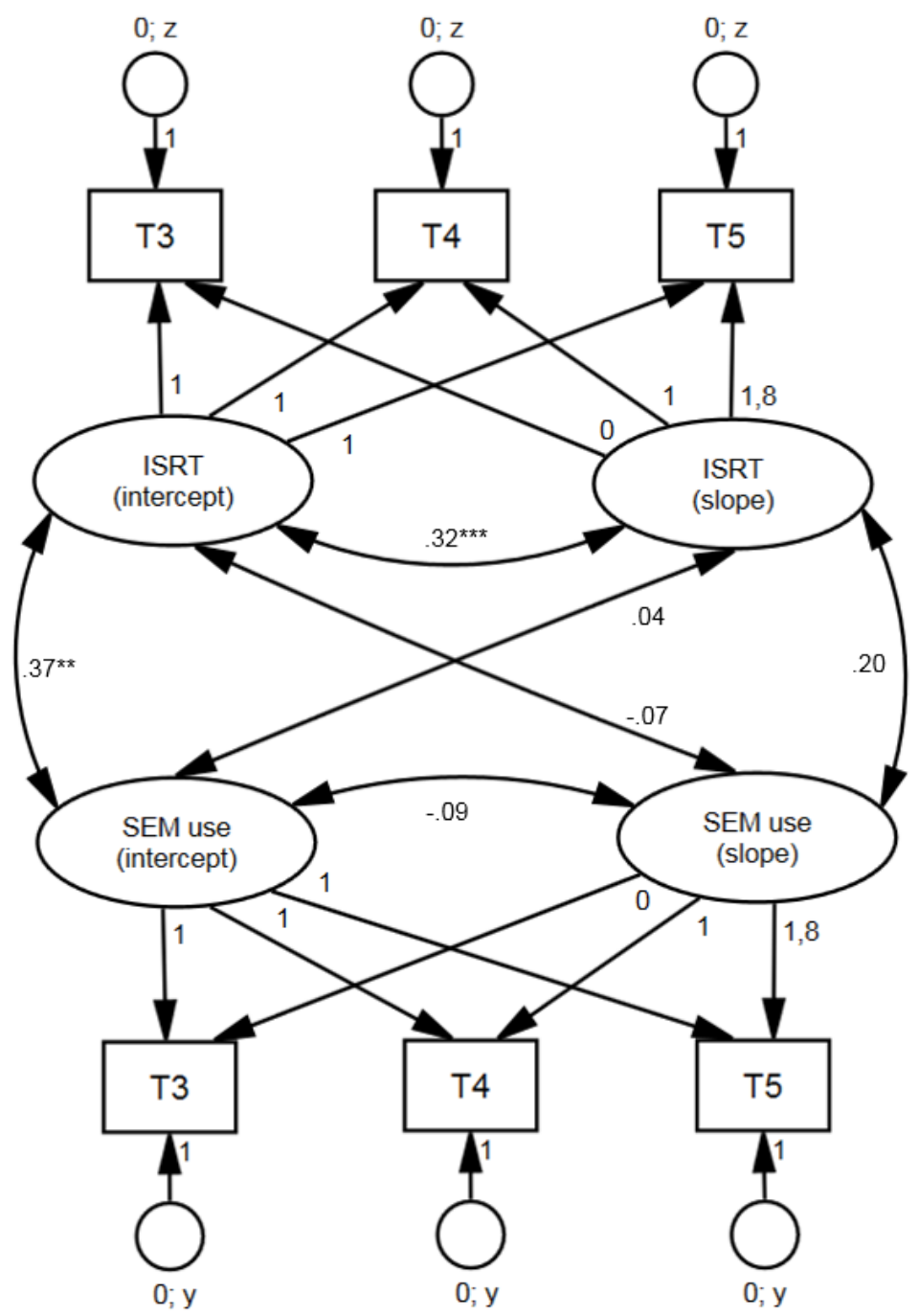

Figure 3. Latent Growth in Female Adolescents' SEM use and the Index of Sexual Risk Taking $(n=365)$.

Note. $* p<.05 . * * p<.01$. 